\title{
Should Macular Lesions Accompanying Spinal Dysraphism be Excised? Analysis of Macular Lesions Accompanying Spinal Dysraphism
}

\author{
Necmettin TUTUNCU1', Goktekin TENEKECI², Sakir UNAL², Necat YILMAZ³, Celal BAGDATOGLU4 \\ ${ }^{1}$ Toros State Hospital, Plastic Surgery Clinic, Mersin, Turkey \\ ${ }^{2}$ Mersin University, School of Medicine, Department of Plastic and Reconstructive Surgery, Mersin, Turkey \\ ${ }^{3}$ Mersin University, School of Medicine, Department of Histology and Embryology, Mersin, Turkey \\ ${ }^{4}$ Mersin University, School of Medicine, Department of Neurosurgery, Mersin, Turkey
}

\section{ABSTRACT}

AIM: To characterize the macular lesions associated with spinal dysraphism and to determine the outcomes of cases in which macular lesions are not excised.

MATERIAL and METHODS: The patient cohort comprised 17 patients with spinal dysraphism who were treated at Mersin University Hospital from 2005 through 2007. Blood and tissue samples were obtained from these patients.

RESULTS: Electron microscopy results of tissue samples obtained from macular lesions are not consistent with those of hemangiomas. Increased numbers of vessels and significant dilatation was noted upon examination by light microscopy. The number of mast cell numbers, blood estradiol levels, expression of tissue inhibitor matrix metalloproteinase-1 (TIMP-1) and vascular endothelial growth factor (VEGF), and dermal collagen fiber diameter were within normal range. Estrogen receptor- $\beta$ was not expressed. The number of endothelial cells expressing Von-Willebrand factor was higher in the macular lesions.

CONCLUSION: The characteristics of macular lesions associated with spinal dysraphism are consistent with those of capillary malformations. We believe that the preservation of these macular lesions during soft tissue reconstruction of spinal dysraphism defects, either by mobilization on a flap or primary closure, does not compromise the viability of the macular region. By preserving these macular lesions, the creation of larger defects during excision is avoided.

KEYWORDS: Capillary malformation, Hemangioma, Spinal dysraphism

ABBREVIATIONS: TIMP-1: Tissue inhibitor matrix metalloproteinase-1, VEGF: Vascular endothelial growth factor.

\section{INTRODUCTION}

A bnormal fusion of the midline neural, vertebral, and mesenchymal structures during embryogenesis is known as spinal dysraphism. Such neural tube defects affect approximately $1-2$ of every 1000 newborns in the United States (1). Current findings show that a multi-gene predisposition and environmental factors such as diabetic milieu and folate status play roles in the development of neural tube defects (4). Early surgical closure of the defects and reconstruction of skin and soft tissue deficits are performed to prevent cerebrospinal fluid leakage and central nervous system infections (2). This procedure involves both neurosurgery and plastic surgery (2). 
The methods presently used for soft tissue reconstruction of myelomeningocele defects include latissimus dorsi flaps (27), rotation-transposition fasciocutaneous flaps (20), bilateral V-Y advancement flaps (15), subcutaneous-based pedicle flaps with bilateral V-Y advancement (14), bilobed flaps (16), lumbar artery perforator flaps (5), dorsal intercostal artery perforator flaps $(2,12,25)$ and simultaneous lumbar artery and dorsal intercostal artery perforator flaps (3). Ideal reconstruction of neural tube defects requires a well-vascularized and flexible bed that will allow a watertight seal without increasing the bulk (19).

Most spinal dysraphism patients have macular lesions around the myelomeningocele or meningocele defects. The question of whether these lesions should be excised constitutes an important dilemma. Most small myelomeningocele defects (diameter $<5 \mathrm{~cm}$ ) can be closed primarily (20), while larger defects require reconstruction with flaps. If the macular lesion around the myelomeningocele defect is excised, the size of the defect will increase. However, if the lesion is not excised and is included in the flap, the survival of the flap can be impaired. This study aims to characterize these macular lesions and to determine the clinical outcomes of patients in which the macular lesions were not excised.

\section{MATERIAL and METHODS}

This study was carried out at Mersin University Hospital. Ethical approval was obtained from the Ethics Committee of Mersin University School of Medicine. The study cohort includes 17 patients with spinal dysraphism who were treated at Mersin University Hospital from 2005 to 2007. Blood and tissue samples were obtained.

\section{Tissue Preparation and Microscopy}

Tissue samples were obtained from two different locations in each patient during defect reconstruction. Samples were divided into two groups according to the location from which the samples were obtained. Group 1 tissue samples $(n=17)$ were obtained from healthy skin. In patients with defects $>5$ $\mathrm{cm}$, reconstruction was performed using rotation flaps, and the normal tissue samples were obtained from the region where the back-cut was made. In patients with defects $<5$ $\mathrm{cm}$, where primary closure is indicated, tissue samples for group 1 were obtained from the farthermost region to the macular discoloration. Group 2 tissue samples $(n=17)$ were obtained from the macular discoloration region at the edge of the defect.

Tissue samples were fixed in $10 \%$ formaldehyde solution for evaluation by light microscopy. The specimens were processed in paraffin blocks, cut into sections, stained with toluidine blue, and examined under a light microscope for mast cell counts. For electron microscopy, tissue samples were fixed in $2.5 \%$ cold glutaraldehyde and embedded in resin (Araldite, Electron Microscopy Sciences, Hatfield, PA, USA). Thin sections were treated with uranyl acetate-lead citrate for contrast and examined under an electron microscope (Jeol JEM 1011, Tokyo, Japan).
Immunohistochemistry using antibodies against Vonwillebrand factor (mouse monoclonal anti-VWF, SC-21784, Santa Cruz Biotechnology, Santa Cruz, CA, USA) and vascular endothelial growth factor (VEGF) (mouse monoclonal antiVEGF, SC-7269, Santa Cruz Biotechnology, Santa Cruz, CA, USA) was used to investigate the expression of these proteins by light microscopy. The expression of estrogen receptor- $\beta$ was also investigated using immunohistochemistry (rabbit polyclonal, anti-estrogen receptor $\beta$, ab3577, Abcam Inc., Cambridge, UK). Strept Avidin-Biotin immunoperoxidase staining was used for immunohistochemical examination. The intensity of staining for Von-Willebrand factor, VEGF, and estrogen receptor- $\beta$ was evaluated by two blinded observers using a photomicroscope (Olympus BX50, Olympus $\mathrm{GmbH}$, Germany). Expression levels were analyzed semiquantitatively. Blood estradiol levels were also measured.

\section{Statistical Analysis}

Statistical analysis was performed using a two-tailed, paired t-test. Differences were considered statistically significant for $p<0.05$. The SPSS 11.5 software package (SPSS Inc., 2000, Chicago, IL, USA) was used for the statistical analyses.

\section{RESULTS}

In our cohort of 17 patients, the mean age at the time of surgery was $4.6 \pm 1.3$ months (range, 2 days -4.5 years). Myelomeningocele was the diagnosis for $82.4 \%$ of the cohort $(n=14)$, while $17.6 \%(n=3)$ was diagnosed as having meningocele. Defects were located in the lumbosacral region $(76.4 \%$; $\mathrm{n}=13$ ), lumbar region (11.8\%; $\mathrm{n}=2$ ), and thoracolumbar region (11.8\%; $n=2)$. The defects were reconstructed using flaps in $70.6 \%(n=12)$ of the cases, while the rest $(29.4 \% ; n=5)$ were closed primarily. The macular regions around the myelomeningocele/meningocele defects were preserved in all cases. The macular lesions were incorporated into the flap in all cases requiring reconstruction using flaps $(n=12)$. All defects were reconstructed successfully, without necrosis over the suture lines. The mean follow-up period was 36 months.

\section{Histopathological Analysis}

\section{Light Microscopy}

The number of mast cells in normal and lesion tissue was 4.58 \pm 2.15 and $6.79 \pm 4.18$, respectively. No statistical difference was observed between the two groups (Student's t-test, $\mathrm{p}=0.062$ ) (Figure 1). Mast cell staining patterns are shown in Figures 2, 3.

\section{Electron Microscopy}

In normal tissue, the nuclei, nucleoli, mitochondria, and melanin granules appeared normal, and a strong complex of intercellular connections was observed (Figures 4, 5). Lesion tissue samples lacked endothelial proliferation, multilamination in the basal membrane, and the accumulation of pericytes and macrophages. The distance between keratinocytes was greater in lesional tissue, and edema was observed between the cells. In addition, extremely large vacuolar structures were seen, sometimes displacing the nucleus peripherally. Apop- 


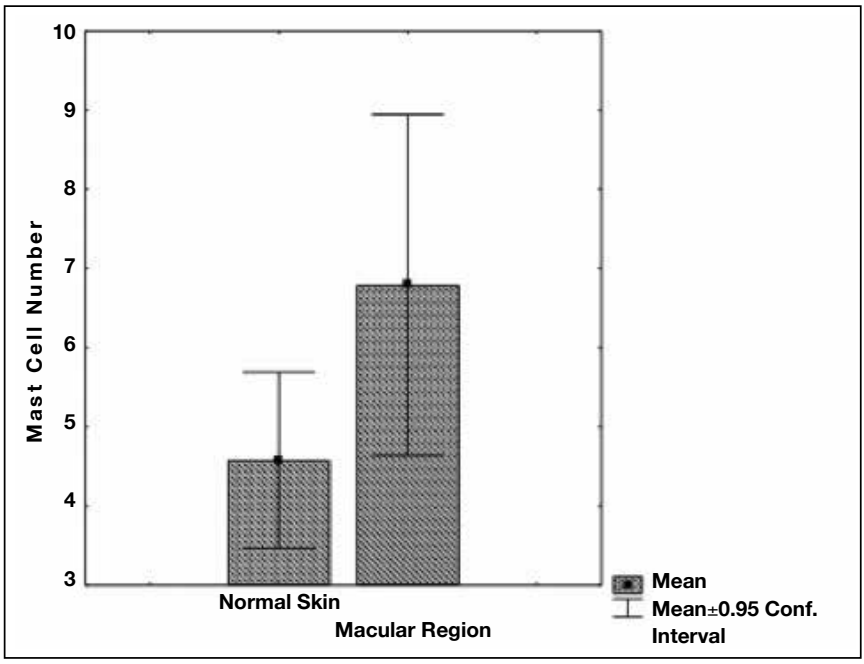

Figure 1: Mean number of mast cells in normal and macular lesion tissues.

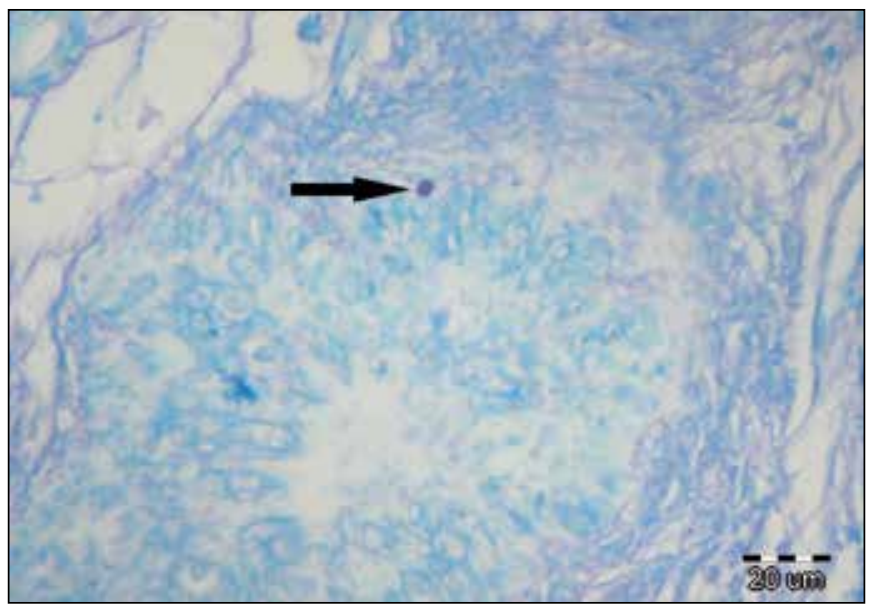

Figure 2: Analysis of toluidine-blue stained sections. Mast-cell staining in normal tissue is shown (Toluidin blue, $\times 400$ ). Arrows indicate mast cells.

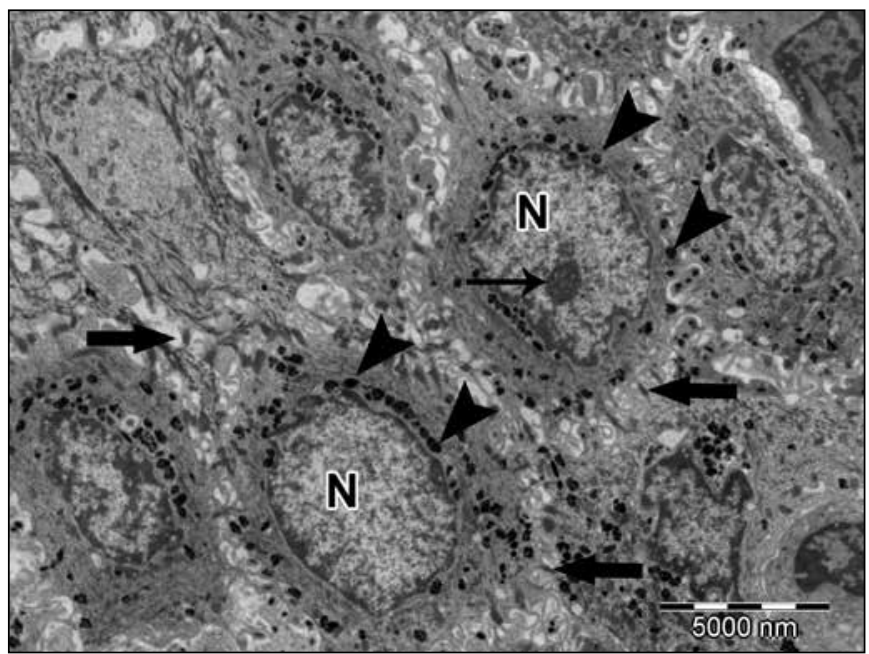

Figure 4: Electron microscopic analysis of normal tissue. Appearance of nucleus $(\mathrm{N})$, nucleolus (Thin arrow), melanin granules (Arrowhead) and intercellular junctional complexes (Arrow) (x5000). totic findings such as organelle degeneration and peripheral heterochromatin condensation were seen in many of the keratinocyte nuclei. Loss of melanin granules was also seen in keratinocytes (Figures 6,7 ). The diameter of dermal collagen was $0.67 \pm 0.19 \mu \mathrm{m}$ and $0.65 \pm 0.09 \mu \mathrm{m}$ in normal and lesion tissue, respectively. However, no statistically significant difference was noted between the two tissue types (Student's t-test, $\mathrm{p}=0.740$ ) (Figure 8), indicating that they are similar with respect to collagen synthesis.

\section{Immunohistochemical Findings}

Von-Willebrand Factor (Factor 8)

The expression of Von-Willebrand factor in normal and lesional tissue was $7.74 \pm 2.40$ and $11.69 \pm 4.60$, respectively. The number of endothelial cells and vessels stained for VonWillebrand factor was significantly greater in Group 2 than in Group 1 (Student's t-test, $p=0.004$ ) (Figure 9). In group 2, we

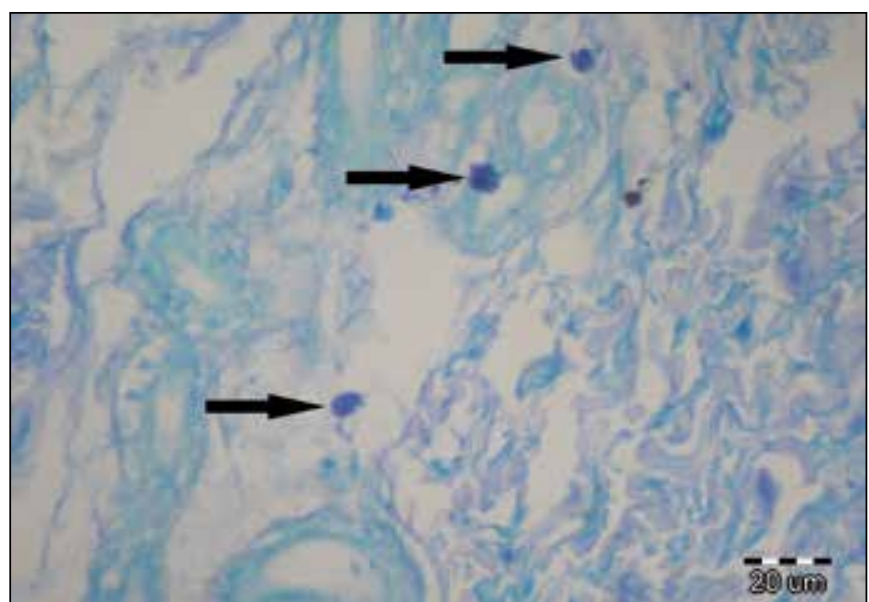

Figure 3: Analysis of toluidine-blue stained sections. Mast-cell staining in macular lesion tissue is shown (Toluidin blue, $\times 400$ ). Arrows indicate mast cells.

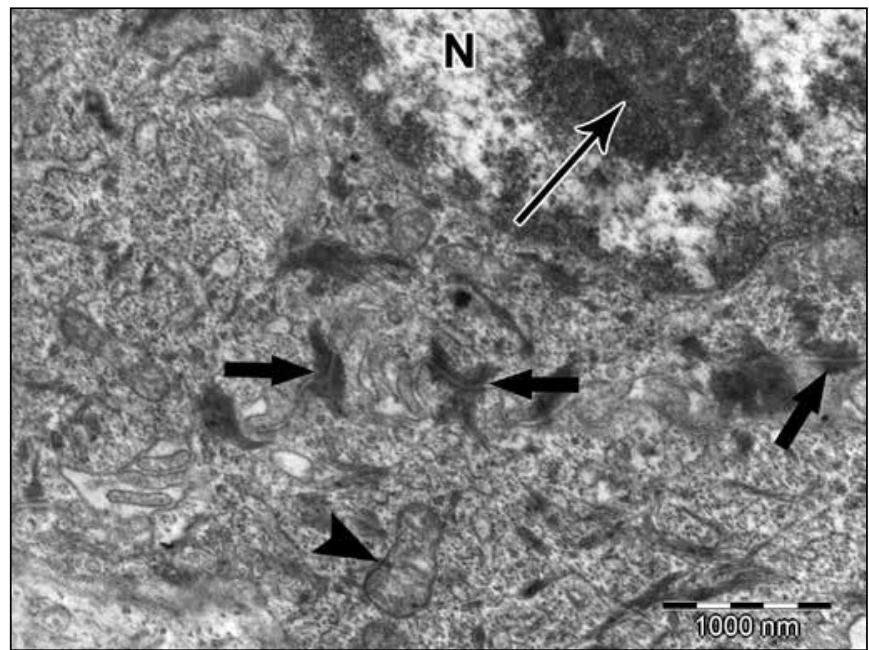

Figure 5: Electron microscopic analysis of normal tissue. The nucleus ( $N$ ), nucleolus (thin arrow), mitochondria (arrowhead), and intercellular junctional complexes (arrows) are seen $(\times 12000)$. 
Tutuncu N. et al: Macular Lesions in Spinal Dysraphism

observed the dilatation of vessels but normal endothelial cells. Representative images of Von-Willebrand factor expression in normal and lesional tissue are shown in Figures 10, 11.

\section{Vascular Endothelial Growth Factor}

The expression of VEGF in groups 1 and 2 was $4.56 \pm 2.19$ and $6.74 \pm 4.13$, respectively, and the difference was not statistically significant (Student's t-test, $p=0.064$ ) (Figure 12). Representative images of VEGF expression in normal and lesional tissue are shown in Figures 13, 14.

\section{Estrogen Receptor- $\beta$}

Estrogen receptor- $\beta$ expression was not observed in either group. Representative images of immunohistochemical analysis of estrogen receptor- $\beta$ expression in normal and lesional tissue are shown in Figures 15, 16.

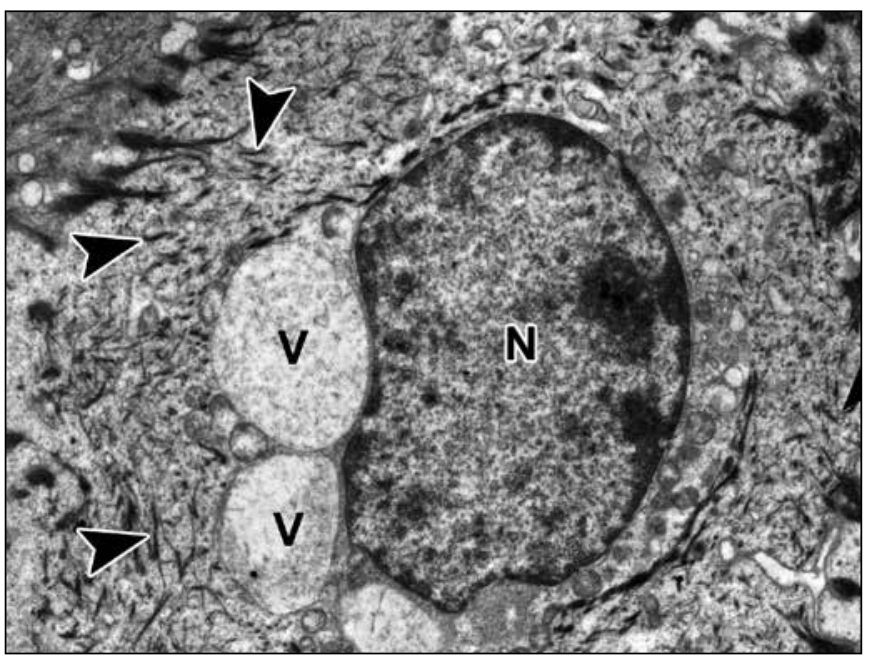

Figure 6: Electron microscopic analysis of macular lesion tissue. Increased hemochromatin density in the periphery of the cell nucleus $(\mathrm{N})$, tonofilament bundles (arrowheads), and wide vacuoles $(V)$ are seen $(\times 12000)$.

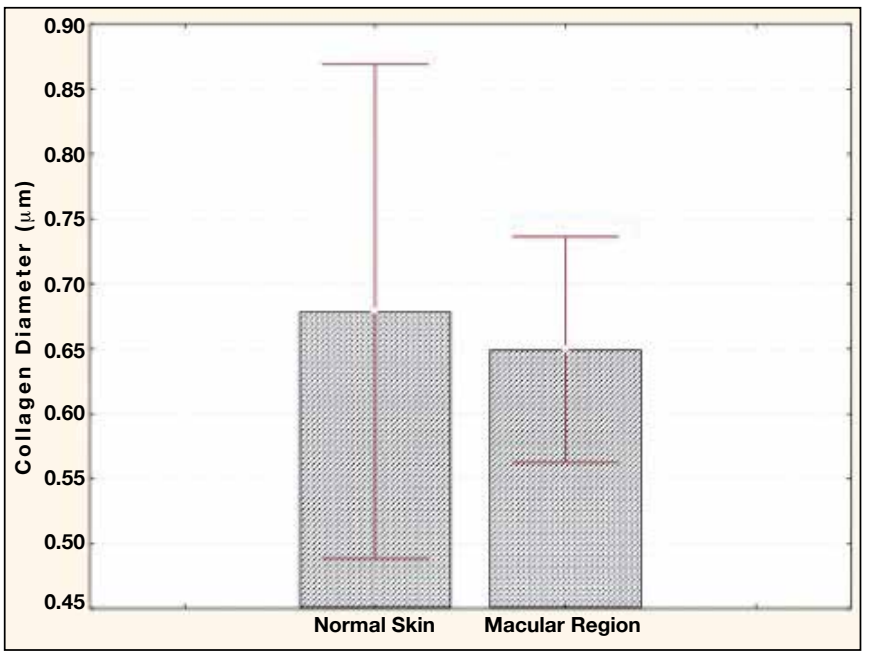

Figure 8: Comparison of mean dermal collagen fiber diameter of dermis in normal and macular lesion tissue.

\section{Biochemical Findings}

The mean blood estradiol level of the study cohort was 16.4 $\mathrm{pg} / \mathrm{mL}$ (normal range, $13.5-59.5 \mathrm{pg} / \mathrm{mL}$ ).

\section{DISCUSSION}

Spinal dysraphism is a general term for abnormal fusion of midline neural, vertebral and mesenchymal structures at embryonic period. Early surgical closure of the defects and reconstruction of skin and soft tissue deficits is performed in order to prevent cerebrospinal fluid leakage and central nervous system infections (2). This is a combined operation of Neurosurgery and Plastic Surgery (2). The Plastic Surgery team attends in the operation after the Neurosurgery team completes vertebral canal closure. Myelomeningocele defects

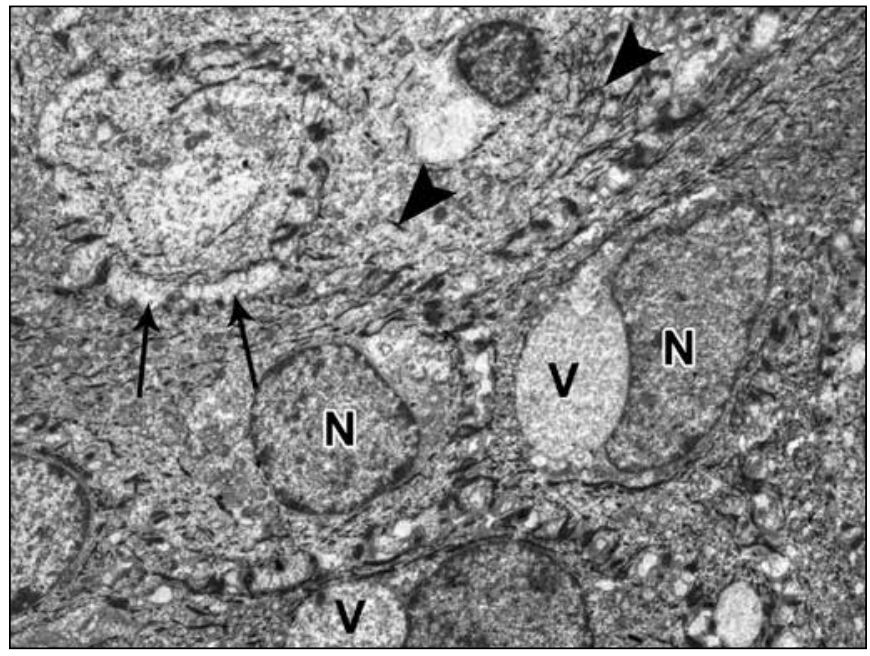

Figure 7: Electron microscopic analysis of macular lesion tissue. Increased hemochromatin density in the periphery of cell nucleus $(\mathrm{N})$, tonofilament bundles (Arrowheads), increase in intercellular distance (Asterisk) and wide vacuoles (V) are seen. $(\times 5000)$

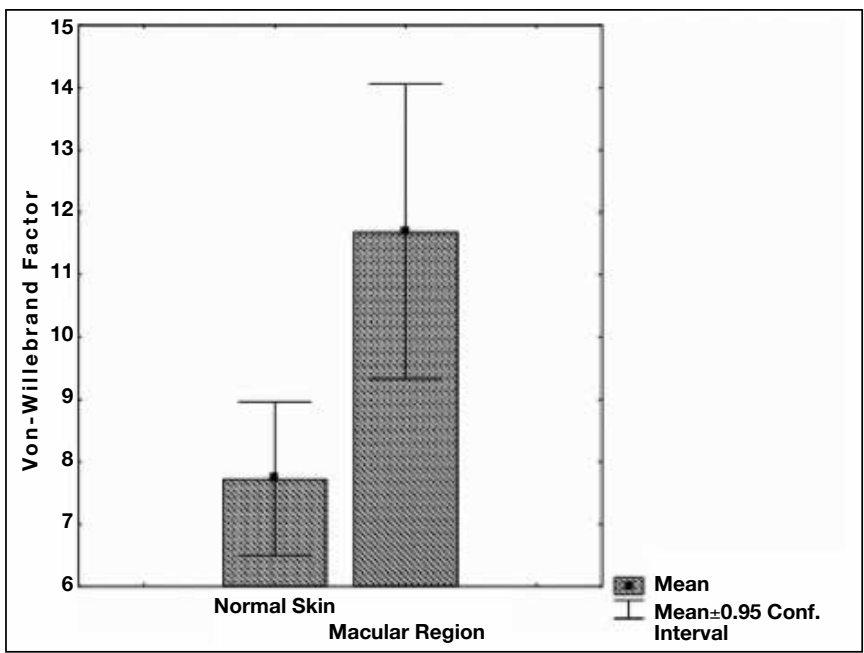

Figure 9: Mean number of blood vessels expressing VonWillebrand factor in normal and macular lesion tissue. 


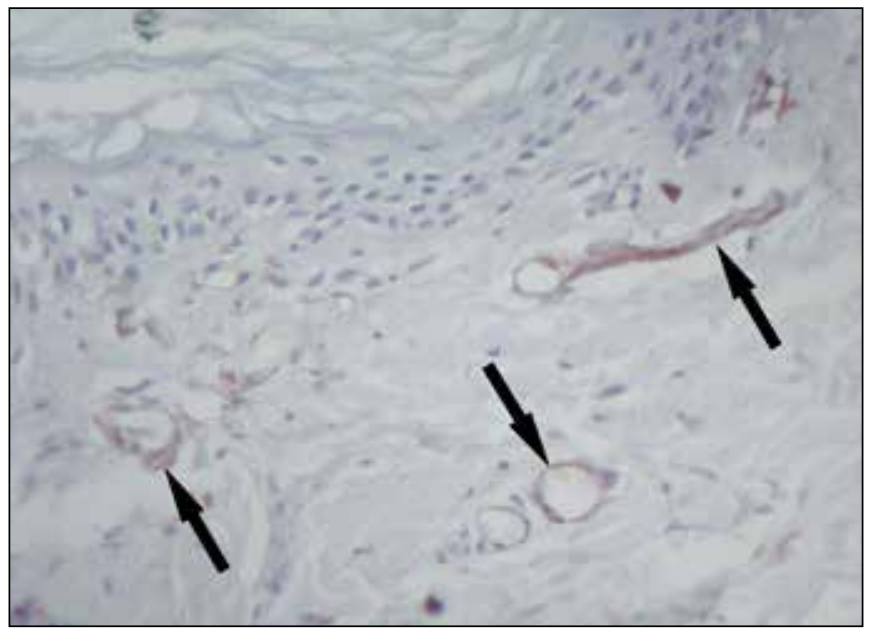

Figure 10: Immunohistochemical staining for Von-Willebrand factor in normal tissue (×600). Vessels (arrow) appear normal.

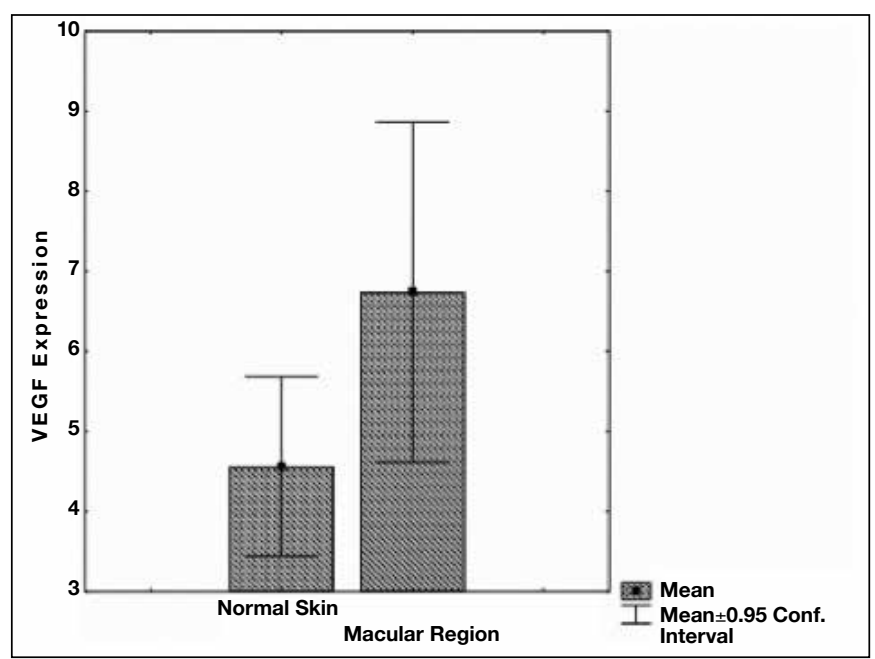

Figure 12: Mean VEGF expression level in normal and macular lesion tissue.

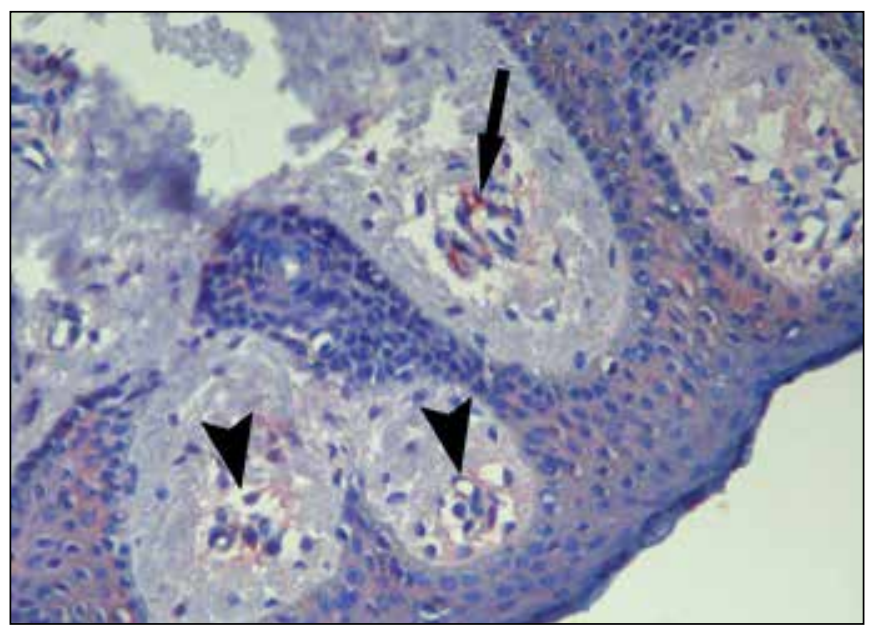

Figure 14: Immunohistochemical staining for VEGF in macular lesion tissue. Stained (arrow) and unstained (arrowhead) vessels are seen $(\times 1200)$.

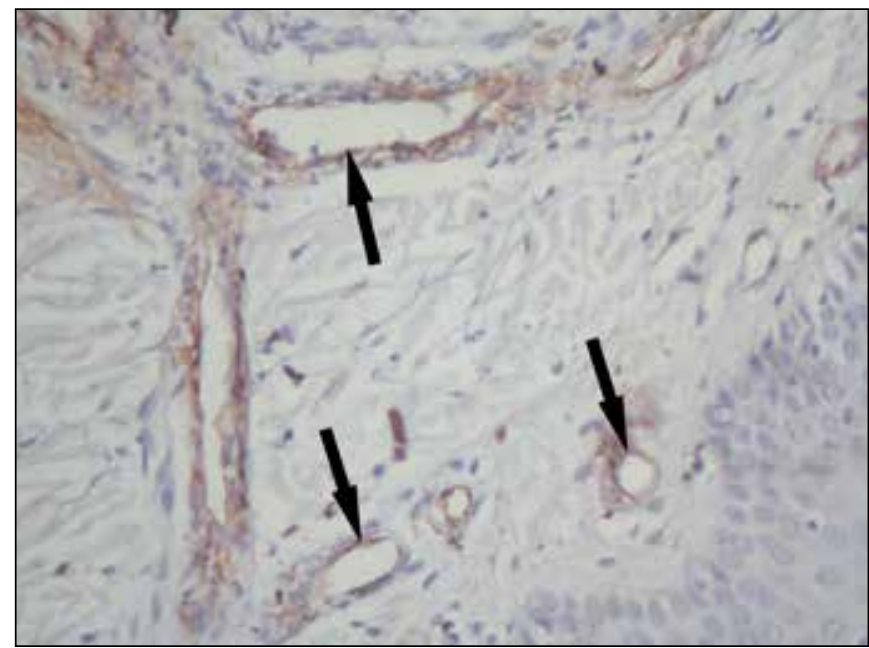

Figure 11: Immunohistochemical staining for Von-Willebrand factor in macular lesion tissue $(\times 1200)$. Vascular structures (arrow) are dilated.

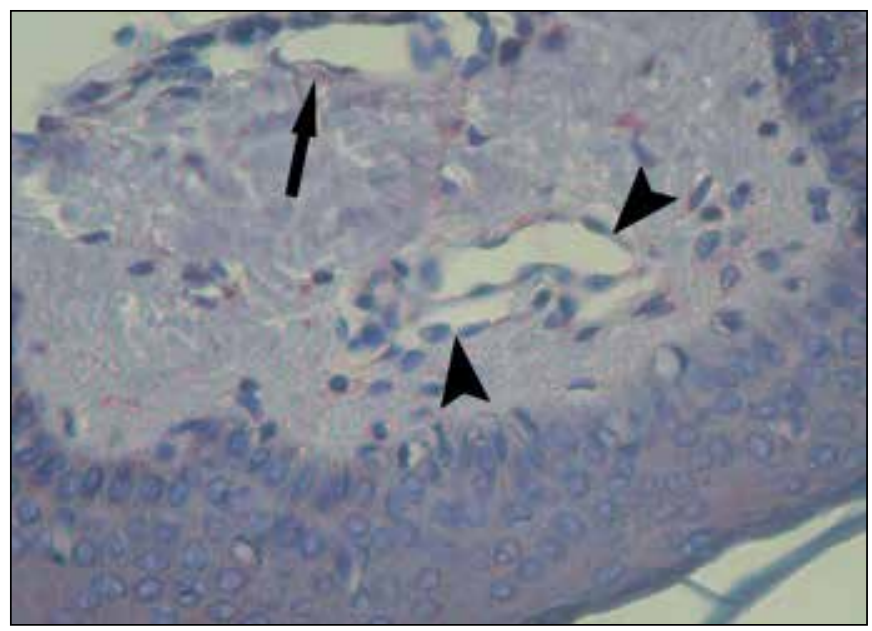

Figure 13: Immunohistochemical staining for VEGF in normal tissue. Stained (arrow) and unstained (arrowhead) vessels are seen $(\times 1200)$.

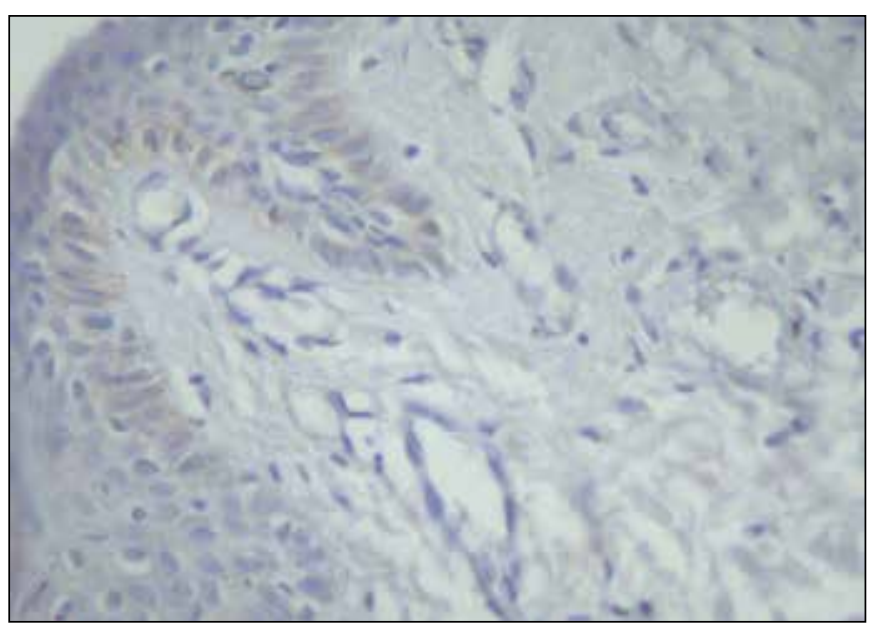

Figure 15: Immunohistochemical staining of estrogen receptor- $\beta$ in normal tissue $(\times 1200)$. 


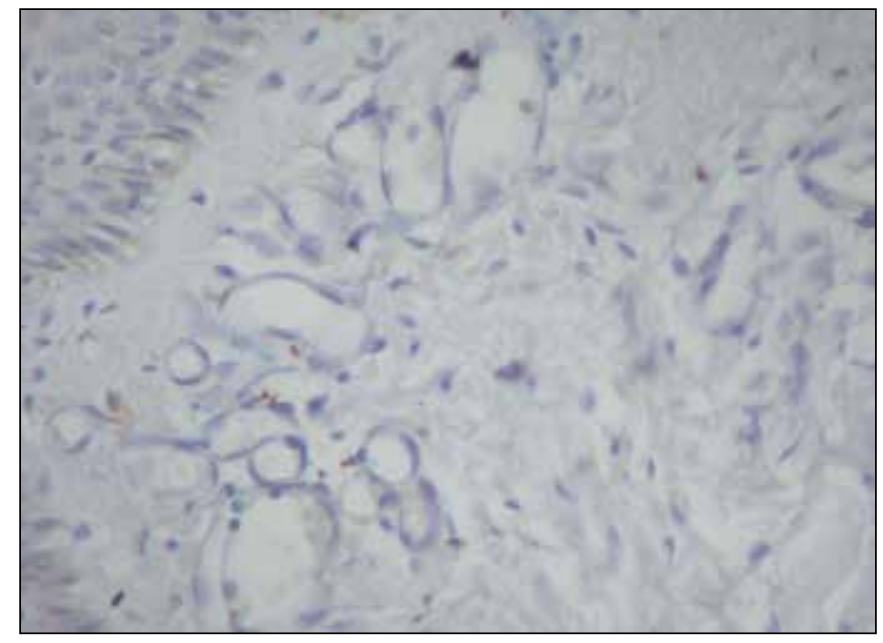

Figure 16: Immunohistochemical staining of estrogen receptor- $\beta$ in macular lesion tissue $(\times 1200)$.

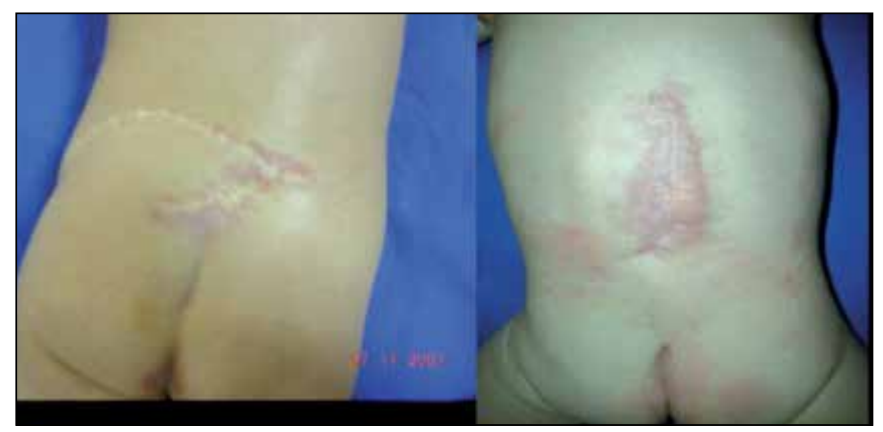

Figure 17: Left: myelomeningocele defect reconstructed using a rotation flap in which the macular lesion is transferred as a part of the planned flap (2 years post-surgery). Right: myelomeningocele defect in which the macular lesions are preserved during reconstruction via primary closure (6 months post-surgery).

with a diameter smaller than $5 \mathrm{~cm}$ are known as small defects and such defects can be closed primarily (20), while larger defects require reconstruction with flaps. Latissimus dorsi flaps (27), rotation-transposition fasciocutaneous flaps (20), bilateral $V-Y$ advancement flaps (15), subcutaneous based pedicle bilateral $\mathrm{V}-\mathrm{Y}$ advancement flap (14), bilobed flaps (16), lumbar artery perforator flaps (5), dorsal intercostal artery perforator flaps $(2,12,25)$, and simultaneous lumbar artery and dorsal intercostal artery perforator flaps (3) have been some of the options reported for soft tissue reconstruction of myelomeningocele defects over the back. Some groups claim the efficacy of placing acellular dermal matrix between neural element repair and skin flaps thus providing reliable and stable soft tissue coverage (11). Various reconstructive options are used in reconstruction of myelomeningocele defects since it is challenging to reconstruct large myelomeningocele defects. In case of preservation and survival of macular lesions around spinal dysraphism, a smaller soft tissue defect will remain and the smaller the defect is the lesser the complications observed. Preservation of the macular lesion around the myelomeningocele defect can decrease wound dehiscence, cerebrospinal fluid leakage, wound infection, and flap failure. However, surgeons usually believe that the region of the macular lesion has low dermal quality, most often choosing to extend the excision into the macular region. We believe that this decision should be made together with the plastic surgery team that will reconstruct the defect. Undiagnosed macular lesions are often present around the skin defect, and excision of these lesions by the neurosurgery team may enlarge the defect unnecessarily, and therefore may require reconstruction with flaps instead of primary reconstruction or requiring harvest of larger flaps which may increase risk of flap necrosis. In this study, our aim is to find answers to the following two questions:

1) What is the diagnosis (vascular pathology) for the macular lesions around spinal dysraphism?

2) If flaps are required for reconstruction of the defects, are the macular lesions reliable for transfer and do they maintain their viability as a part of the planned flap?

The second question may be answered based on our experience and based on the answer of the first question.

Previous studies of hemangioma histology have revealed endothelial proliferation, multi-lamination in basal membranes and pericytes, and macrophage and mast cell accumulation $(9,18,22-24)$. However, biopsy specimens obtained from the macular lesions in the present study exhibited none of these histological findings. Instead, the distance between keratinocytes is greater in hemangiomas than in normal tissue, which may be related to increased intercellular edema. In addition, we observed that keratinocytes lacked melanin granules. These results are not consistent with the features of hemangiomas. Examination of the macular lesions by light microscopy revealed increased numbers and significant dilatation of vessels, with normal endothelial cells. These findings are similar to those reported in capillary malformations $(18,28)$.

Many reports state that mast cells are abundant in hemangiomas $(9,22-24)$. Glowacki and Mulliken have reported that hemangiomas in the proliferative phase contain more mast cells than those in the involuting phase, in vascular malformations, and in normal skin (10). While the number of mast cells is not elevated in vascular malformations (10), they are 30-40 times more prevalent in hemangiomas than in normal tissue (17). In this study, the mean age at the time of surgery was 4.6 \pm 1.3 months; if the lesions were hemangiomas, the number of mast cells would have been very high, since the lesions in patients of this age are expected to be in the proliferative phase. However, no significant difference was observed in the number of mast cells between the two groups (Figure 1).

Comparison of normal skin to that of macular lesions revealed no difference in type-4 collagen and fibronectin, the major structural components of skin (6). Our results support this finding, as the diameter of collagen fibers did not differ significantly between the two groups (Figure 8).

Sasaki et al. reported elevated levels of estrogen receptor- $\beta$ and serum estradiol levels in patients with hemangioma (26). Estrogen receptor- $\beta$ levels are minimal in normal skin and 
capillary malformations (26). We observed that both normal and lesion tissue samples did not express estrogen receptor- $\beta$ (Figures 15, 16), and estradiol levels were within the normal range.

VEGF stimulates angiogenesis and endothelial cells, thereby increasing hyperplasia and mitosis of endothelial cells (8). Immunohistochemical analysis by Takahashi et al. showed that VEGF expression is elevated in proliferative hemangiomas but depressed or not expressed at all in vascular malformations (21). However, in our study, VEGF expression did not differ significantly between normal and lesion tissues (Figures 12-14), suggesting that these lesions are not proliferating hemangiomas.

Von-Willebrand factor, CD 34, and CD 31 are markers for vascular endothelium and are highly expressed in proliferative hemangiomas (29). Takahashi et al. reported that Von-Willebrand factor is present in all types of vascular malformations (21). Our study shows significantly higher numbers of endothelial cells expressing Von-Willebrand factor in macular regions compared to normal skin. This finding reflects the increased vascularization in macular regions. Significant dilatation of vessels was noted using light microscopy, a feature distinguishing capillary malformations from hemangiomas.

Our study reveals that melanin pigment is present in normal cells but absent in the macular region. This absence of melanin granules may be secondary to insufficient melanocyte migration, the absence of melanocytes or melanocyte dysfunction. As with neural structures, melanocytes originate from ectoderm during embryogenesis. Melanocytes are localized in the stratum basale (13). The elevated numbers and dilatation of blood vessels observed in the macular region may result from the absence of melanin pigment in this region. However, this possibility does not explain the etiology and pathogenesis of this change in blood vessels. The absence of melanin granules in the macular region may be caused by a decrease in the migration of melanocytes toward the region of the neural tube defect. Because the neural tube and melanocytes both originate from ectoderm, the same mechanism likely underlies the defect in neural tube closure and the absence of melanin granules in the macular region near the neural tube defect.

Table I: Histopathological and Immunohistochemical Comparisons of Group 1 and Group 2

\begin{tabular}{lll}
\hline & $\begin{array}{l}\text { Group 1 (Biopsy Obtained } \\
\text { From Healthy Skin) }\end{array}$ & $\begin{array}{l}\text { Group 2 (Biopsy Obtained From } \\
\text { Macular Discoloration Region at } \\
\text { the Edge of Defect) }\end{array}$ \\
\hline Endothelial Proliferation & Not Visualized & Not Visualized \\
\hline Multi-lamination in Basal Membrane & Not Visualized & Not Visualized \\
\hline Mast Cell Count & No Statistical Difference & No Statistical Difference \\
\hline Vessel Dilatation & Not Visualized & Visualized \\
\hline Increase in Vascularity (Based on Von-Willebrand Factor & Significantly Low & Significantly High \\
\hline Staining Character) & No Statistical Difference & No Statistical Difference \\
\hline Estrogen Receptor- $\beta$ Levels & No Statistical Difference & No Statistical Difference \\
\hline VEGF Levels & No Statistical Difference & No Statistical Difference \\
\hline TIMP-1 Levels & No Statistical Difference & No Statistical Difference \\
\hline Collagen Synthesis (Based on Collagen Fiber Diameters) & Within Normal Range & \\
\hline Blood Estradiol Levels & & \\
\hline
\end{tabular}

Table II: Histopathological and Immunohistochemical Comparison of Hemangiomas and Capillary Malformations

\begin{tabular}{|c|c|c|}
\hline & Hemangioma & Capillary Malformation \\
\hline Endothelial Proliferation & Exist & Does Not Exist \\
\hline Multi-lamination in Basal Membrane & Exist & Does Not Exist \\
\hline Mast Cell Count & Increased & Normal \\
\hline Vessel Dilatation & Not Visualized & Visualized \\
\hline Increase in Vascularity & Exist & Exist \\
\hline Estrogen Receptor- $\beta$ Levels & High & Normal \\
\hline Blood Estradiol Levels & High & Normal \\
\hline VEGF Levels & High & Normal \\
\hline TIMP-1 Levels & Normal in Proliferative Phase, Increased in Involutional Phase & Normal \\
\hline Collagen Synthesis & Increased & Normal \\
\hline
\end{tabular}


The macular lesions we observed in this study did not become paler or disappear during follow-up. However, macular lesions in hemangiomas become paler over time, and vascular structures are replaced by fibrous tissue (7). Unlike hemangiomas, lesions in capillary malformations show a growth pattern that is directly proportional to the child's development, and they do not become paler (18). Myelomeningocele defects with a diameter less than five centimeters can be safely closed by preserving the macular lesions around the myelomeningocele defect without a delay in wound healing or wound dehiscence (Figure 17). In cases where local flaps were required for reconstruction of the myelomeningocele defects, the macular lesions maintained their viability as a part of the planned flap (Figure 17). This macular area is believed to be reliable when transferred on a flap.

Table I summarizes the histological and immunohistochemical findings of this study. Table II compares the histological and immunohistochemical properties of hemangiomas and capillary malformations.

The results of this study indicate that the macular region associated with spinal dysraphism is not devoid of a vascular supply. Histological analysis shows that the papillary dermis of macular lesions is rich in blood vessels. Of the 17 patients in the study cohort, 12 underwent reconstruction using flaps (70.6\%), while $5(29.4 \%)$ underwent primary closure. The macular region around the soft tissue defect was preserved in all cases. In all 12 cases reconstructed using flaps, the macular lesion was incorporated into the flap. All defects were reconstructed successfully, without necrosis, even in the macular lesions. We believe that the preservation of macular lesions during soft tissue reconstruction of spinal dysraphism defects, whether through mobilization on a flap or primary closure, does not compromise the viability of macular regions.

\section{CONCLUSION}

We observed that the number of mast cells, diameter of collagen fibers, and expression of estrogen receptor- $\beta$, estradiol, VEGF, and Von-Willebrand Factor in the macular region around spinal cord anomalies were consistent with those of capillary malformations. Histological analysis demonstrated that the papillary dermis of these macular lesions were rich in blood vessels. We believe that the preservation of macular lesions during soft tissue reconstruction of spinal dysraphism defects, whether by mobilizing on a flap or primary closure, does not compromise the viability of the macular region. Such preservation avoids the creation of larger defects due to unnecessary excision of macular lesions that may require more complicated surgeries.

\section{- REFERENCES}

1. Au KS, Northruo H, Kirkpatrick TJ, Volcik KA, Fletcher JM, Townsend IT, Blanton SH, Tyerman GH, Villarreal G, King TM: Promoter genotype of the platelet- derived growth factor receptor-alpha gene shows population stratification but not association with spina bifida meningomyelocele. Am J Med Genet A 139: 194-198, 2005
2. Basterzi Y, Tenekeci G: Dorsal intercostal artery perforator propeller flaps: A reliable option in reconstruction of large meningomyelocele defects. Ann Plast Surg 76(4):434-437, 2016

3. Cologlu H, Ozkan B, Uysal AC, Çologlu O, Borman H: Bilateral propeller flap closure of large meningomyelocele defects. Ann Plast Surg 73(1):68-73, 2014

4. Copp AJ, Santier P, Greene NDE: Neural tube defects-recent advances, unsolved questions and controversies. Lancet Neurol 12(8):799-810, 2013

5. El-Sabbagh $\mathrm{AH}$, Zidan AS: Closure of large myelomeningocele defects by lumbar artery perforator flaps. J Reconstr Microsurg 27(5):287-294, 2011

6. Finley JL, Clark RA, Colvin RB, Blackman R, Noe J, Rosen S: Immunofluorescent staining with antibodies to factor VIII, fibronectin, and, collagenous basement membrane protein in normal human skin and port wine stains. Arch Dermatol 118: 971-975, 1982

7. Finn MC, Glowacki J, Mulliken JB: Congenital vascular lesions: Clinical application of a new classification. J Pediatr Surg 18: 894-900, 1983

8. Folkman J: Clinical application of research on angiogenesis. New Engl J Med 333:757-1763, 1995

9. Folkman J, Klagsburn M: Angiogenic factors. Science 235: 442-447, 1987

10. Glowacki J, Mulliken JB: Mast cells in hemangiomas and vascular malformations. Pediatrics 70(1):48-51, 1982

11. Hill SM, Elwood ET, Lin J: Closure of meningomyelocele defects using acellular dermal matrix. J Neurosurg Pediatrics 9: 156-160, 2012

12. Isik D, Tekes L, Eseoglu M, Isik Y, Bilici S, Atik B: Closure of large myelomeningocele defects using dorsal intercostal artery perforator flap. Ann Plast Surg 67(2):159-163, 2011

13. Junqueira LC, Carneiro J, Kelley RO: Basic Histology. Connecticut: Appleton \& Lange, 1998

14. Kesan K, Kothari P, Gupta R, Gupta A, Karkera P, Ranjan R, Mutkhedkar K, Sandlas G: Closure of large meningomyelocele wound defects with bilateral V-Y advancement: Our experience and review of literature. Eur J Pediatr Surg 25: 189-194, 2015

15. Komuro $Y$, Yanai A, Koga $Y$, Seno $H$, Inoue M: Bilateral modified $\mathrm{V}-\mathrm{Y}$ advancement flaps for closing meningomyelocele defects. Ann Plast Surg 57(2):195-198, 2006

16. Lapid O, Rosenberg L, Cohen A: Meningomyelocele reconstruction with bilobed flaps. Br J Plast Surg 54(7):570572, 2001

17. Mulliken, JB: Pathogenesis of hemangiomas. In: Mulliken JB, Young MA (eds), Vascular Birthmarks: Hemangiomas and Malformations. Philadelphia: Saunders, 1988:63-76

18. Mulliken JB, Glowacki J: Hemangiomas and vascular malformations in infants and children: A classification based on endothelial characteristic. Plast Reconstr Surg 69:412422, 1982

19. Quong WL, Bulstrode NW, Thompson DNP: The use of de-epithelialized skin flap in the surgical repair of terminal myelocystoceles. Childs Nerv Syst 31: 473-479, 2015 
20. Selcuk CT, Civelek B, Bozkurt M, Kapi E, Kuvat SV: Reconstruction of large meningomyelocele defects with rotation-transposition fasciocutaneous flaps. Ann Plast Surg 69(2):197-202, 2012

21. Takahashi K, Mulliken JB, Kozakewich HP, Rogers RA, Folkman J, Ezekowitz RA: Cellular markers that distinguish the phases of hemangioma during infancy and childhood. $J$ Clin Invest 93(6):2357-2364,1994

22. Tan ST: Cellular and molecular basis of haemangioma. Wellington: University of Otago, 2001

23. Tan ST, Velickovic M, Rüger BM, Davis PF: Cellular and extracellular markers of hemangioma. Plast Reconstr Surg 106(3): 529-538, 2000

24. Tan ST, Wallis RA, He Y, Davis PF: Mast cells and hemangioma. Plast Reconstr Surg 113(3): 999-1011, 2004
25. Tenekeci G, Basterzi Y: Reliability of extended dorsal intercostal artery perforator propeller flaps for reconstruction of large myelomeningocele defects. J Plast Reconstr Aesthet Surg 70(1):60-66, 2017

26. Ulusoy MG, Kocer U, Sungur N, Karaaslan O, Kankaya $Y$, Ozdemir, G, Gumus M: Closure of meningomyelocele defects with bilateral modified V-Y advancement flaps. Ann Plast Surgery 54 (6): 640-644, 2005

27. VanderKolk CA, Adson MH, Stevenson TR: The reverse latissimus dorsi muscle flap for closure of meningomyelocele. Plast Reconstr Surg 81(3):454-456, 1988

28. Waner M, Suen JY: A classification of congenital vascular lesions. In: Waner M, Suen JY (eds), Hemangiomas and Vascular Malformations of the Head and Neck. New York: Wiley-Liss, 1999: 1-12

29. Yu Y, Flint AF, Mulliken JB, Wu JK, Bischoff J: Endothelial progenitor cells in infantile hemangioma. Blood 103(4):13731375,2004 